\title{
Colaboração interprofissional na Estratégia Saúde da Família: implicações para a produção do cuidado e a gestão do trabalho
}

\author{
Interprofessional collaboration in the Family Health Strategy: \\ implications for the provision of care and work management
}

Caroline Guinoza Matuda ${ }^{1}$

Nicanor Rodrigues da Silva Pinto ${ }^{2}$

Cleide Lavieri Martins ${ }^{3}$

Paulo Frazão ${ }^{3}$

${ }^{1}$ Programa de PósGraduação em Saúde Pública, Faculdade de Saúde Pública, Universidade de São Paulo (USP). São Paulo SPBrasil.matuda@usp.br ${ }^{2}$ Departamento de Medicina Preventiva, Universidade Federal de São Paulo.

${ }^{3}$ Departamento de Prática de Saúde Pública, Faculdade de Saúde Pública, USP.

\begin{abstract}
Interprofessional collaboration is seen as a resource for tackling model of care and workforce problems. The scope of this study was to understand the perception about the shared work and interprofessional collaboration of professionals who work in primary health care. A qualitative study was conducted in São Paulo city. In-depth interviews were performed with professionals from distinct categories who worked in the Family Health Strategy and Support Center for Family Health. The results highlighted the empirical 'professional interaction' and 'production goals' categories. The forms of interaction, the role of specialized matrix support and the perspective in which production goals are perceived by the professionals pointed to tensions between traditional professional logic and collaboration logic. It also revealed the tensions between a model based on specialized procedures and a more collaborative model centered on health needs of families and of the community. The sharing of responsibilities and practices, changes in the logic of patient referral to specialized services and inadequate organizational arrangements remain major challenges to the integration of interprofessional collaboration for the development of new care practices.

Key words Interprofessional relations, Cooperative behavior, Primary health care
\end{abstract}

Resumo A colaboração interprofissional vem sendo apontada como um recurso para o enfrentamento dos problemas do modelo de atenção e da força de trabalho. O objetivo do estudo foi captar a percepção de profissionais que atuam na atenção primária à saúde sobre o trabalho compartilhado e a colaboração interprofissional. Uma pesquisa qualitativa foi conduzida no município de São Paulo, mediante a realização de entrevistas em profundidade com profissionais de distintas categorias que atuam na Estratégia Saúde da Familia e no Núcleo de Apoio à Saúde da Família. Os resultados permitiram evidenciar as categorias: 'interação profissional' e 'metas de produção'. As formas de interação, o papel do apoio especializado matricial e o modo como as metas de produção são percebidas apontaram para tensões entre a lógica profissional tradicional e a da colaboração; e entre um modelo centrado em procedimentos especializados e outro mais colaborativo, focado nas necessidades de saúde das famílias e da comunidade. $O$ compartilhamento de responsabilidades e práticas, a alteração da lógica dos encaminhamentos e a insuficiência de dispositivos organizacionais permanecem como importantes desafios para a inserção da colaboração interprofissional no desenvolvimento de novas práticas de produção do cuidado.

Palavras-chave Relações interprofissionais, Comportamento cooperativo, Atenção Primária à Saúde 


\section{Introdução}

O Relatório Mundial de Saúde, divulgado em 2008, reacendeu a importância da atenção primária à saúde (APS) como estratégia para impulsionar as reformas dos sistemas de saúde nos diferentes países do mundo ${ }^{1}$. A equidade no acesso, a efetividade dos serviços, a eficiência no uso de recursos e a capacidade de resposta diante das necessidades da população são alguns dos aspectos chaves para o desenvolvimento dos sistemas de saúde, sendo a força de trabalho em saúde um componente importante dessas reformas ${ }^{2}$. Nesse contexto, a colaboração interprofissional tem sido apontada como um recurso que pode ser mobilizado para enfrentar problemas do modelo de atenção e da força de trabalho, e contribuir para elevar a efetividade dos sistemas de saúde ${ }^{3}$.

Colaboração interprofissional é um termo utilizado para descrever a natureza da interação entre profissionais de diferentes campos do conhecimento, proporcionando uma atenção à saúde mais abrangente. Está relacionada ao cuidado integral, se aproxima de práticas participativas e de relacionamentos pessoais mútuos e recíprocos entre os integrantes das equipes, contrapondo-se às relações tradicionais hierarquizadas. Envolve um constante processo de comunicação e de tomada de decisões, que permite que os conhecimentos e habilidades de diferentes profissionais atuem de forma sinérgica com o usuário e a comunidade ${ }^{4-7}$.

Embora condição importante, uma maior variedade de profissionais compondo equipes de saúde não assegura per si a qualificação da assistência e a mudança organizacional da atenção: ${ }^{8}$. Para este fim, novas configurações de trabalho vêm sendo propostas, propiciando a reflexão sobre as características do processo de interação entre os profissionais das equipes e aspectos que interferem no trabalho cooperado. Esta compreensão é importante para fornecer subsídios no campo do planejamento e gestão dos serviços de saúde ${ }^{6}$.

No Brasil, os princípios e as diretrizes da APS em sua versão mais abrangente vêm sendo assumidos de forma crescente ao longo dos últimos anos, período no qual a Saúde da Família vem se constituindo como uma das principais estratégias dos gestores do Sistema Único de Saúde (SUS), na perspectiva de se efetivar os princípios da universalidade e da integralidade da atenção e reorganizar a atenção?.

Além dos profissionais da equipe mínima (médico, enfermeiro, auxiliar de enfermagem e agente comunitário de saúde), pode-se contar também, com a participação de profissionais de diferentes áreas do conhecimento, como os da equipe de saúde bucal e do Núcleo de Apoio à Saúde da Família (NASF) ${ }^{10}$.

O NASF foi criado com o objetivo de apoiar a inserção da Estratégia Saúde da Família (ESF) na rede de serviços e ampliar o escopo de suas ações. É constituído por uma equipe multiprofissional (de diferentes áreas de conhecimento), atuando em conjunto, compartilhando e apoiando as práticas de saúde nos territórios sob responsabilidade das equipes de saúde da família ${ }^{11}$. A composição da equipe de NASF é definida pelos gestores municipais, mediante demandas reconhecidas em cada território e outros critérios de prioridades. Segundo norma federal, os profissionais que podem compor as equipes de NASF são: assistente social, farmacêutico, fisioterapeuta, fonoaudiólogo, médico acupunturista, médico geriatra, médico ginecologista/obstetra, médico homeopata, médico internista (clínica médica) médico pediatra, médico psiquiatra, médico do trabalho, médico veterinário, profissional/professor de educação física, profissional com formação em arte e educação (arte educador), profissional de saúde sanitarista, psicólogo, nutricionista e terapeuta ocupacional ${ }^{12}$.

Uma das ferramentas utilizadas para organizar e fortalecer o trabalho da Estratégia Saúde da Família (ESF) e o NASF é o chamado apoio matricial ${ }^{13}$. Este termo refere-se ao suporte assistencial e técnico-pedagógico oferecido por uma retaguarda especializada (apoio) para equipes de referência que são compostas por profissionais considerados essenciais na condução de problemas de saúde, responsáveis pelo cuidado longitudinal de certo número de casos e/ou famílias ${ }^{14}$.

Nesse sentido, o apoio matricial é considerado um arranjo organizacional cujo principal objetivo seria ampliar a clínica com a agregação, de forma dialógica, de outras especialidades e profissões, para a construção compartilhada de projetos terapêuticos sob uma abordagem integral $^{13,14}$. Em consequência, instrumentos de trabalho que privilegiem a comunicação transversal na equipe e entre equipes, e técnicas relacionais que permitam uma clínica compartilhada são necessários ${ }^{11}$.

Por reforçar as necessidades de articulação do conhecimento nas equipes, de aprimoramento da interação entre seus integrantes, de desenvolvimento de novos conhecimentos e da prática de novos processos de trabalho - que tenham por base o território de abrangência de suas equipes 
de referência (ESF) -, o NASF se constitui como um recurso essencial para a reorganização dos serviços e a redefinição do modelo de prática iniciado pela ESF.

Para tanto, uma condição importante seria o aprendizado para lidar com as dinâmicas relacionais e os processos de interação com o outro, abrangendo não apenas a relação entre as equipes e os usuários, mas também a relação entre os membros das equipes ${ }^{15}$. As formas de comunicação e de interação entre os profissionais podem ser importante fonte de conflitos ou de colaboração interprofissional ${ }^{13}$. Nesse sentido, a investigação de aspectos relativos à interação profissional no âmbito da ESF e NASF pode auxiliar na identificação tanto dos elementos de suporte, como dos que representam barreiras à prática colaborativa, e oferecer subsídios para o planejamento de ações no campo da gestão do trabalho na atenção primária.

O objetivo deste estudo foi analisar a percepção de profissionais que atuam na atenção primária (Estratégia Saúde da Família e Núcleo de Apoio à Saúde da Família) sobre o trabalho compartilhado e a colaboração interprofissional.

\section{Métodos}

Esta investigação se desenvolveu por meio de um estudo descritivo-exploratório, com abordagem qualitativa, realizado no município de São Paulo com profissionais do NASF e da ESF.

Nesse município, as equipes da Estratégia Saúde da Família (ESF) e do NASF são contratadas e gerenciadas por organizações sociais, pessoas jurídicas de direito privado, sem fins lucrativos, que mantém contratos de gestão com a Secretaria Municipal da Saúde ${ }^{16,17}$. As equipes da ESF e do NASF são alocadas nas unidades de saúde da família municipais e realizam suas atividades de acordo com os princípios e diretrizes para esta estratégia. O processo de implantação da ESF em São Paulo teve início em 1996, e do NASF, em 2008. Nesse ano, o município apresentava 84 equipes de NASF.

Para iniciar o estudo, uma amostra intencional de casos considerados extremos foi selecionada. Neste tipo de seleção procura-se identificar casos mais distintos situados nas extremidades do universo de casos, a fim de reter as principais polaridades presentes no $\mathrm{campo}^{18}$. Propiciou-se com isso uma maior variedade de experiências e situações de interação profissional na Estratégia Saúde da Família.
Para tanto, a seleção dos participantes foi realizada em quatro etapas. Na primeira, foram selecionadas as categorias profissionais; na segunda, a região da cidade; na terceira, os entrevistados do NASF; e na quarta etapa, os entrevistados das equipes de referência (ESF).

A partir dos relatórios de procedimentos, realizados pelos profissionais do NASF, consolidados no período de maio a dezembro de 2010, foi apurada a razão de consultas compartilhadas com a ESF, pelo número total de consultas, por categoria profissional. Profissionais médicos especialistas atuando como apoiadores (acupunturistas, ginecologistas, homeopatas, pediatras e psiquiatras) não foram incluídos na seleção por se tratar de uma interação com a ESF que poderia ser considerada de natureza intraprofissional. Foram selecionadas a categoria profissional "Assistente Social", por apresentar valores elevados de consulta compartilhada (cerca de duas consultas em cada dez); a categoria "Fisioterapeuta", por expressar um valor intermediário (uma em cada dez); e "Fonoaudiólogo", pelo valor mais baixo (menos de uma em cada 10).

$\mathrm{Na}$ segunda etapa, a região Sul foi selecionada por apresentar maior número de equipes NASF implantadas e maior número de profissionais das categorias selecionadas.

Para a identificação dos casos extremos dentro dos grupos profissionais (assistente social, fisioterapeuta e fonoaudiólogo), o indicador de consulta compartilhada foi calculado para cada profissional das categorias selecionadas pertencente a equipes alocadas na Coordenadoria Regional de Saúde Sul do Município. Como técnica de ordenamento visando ao convite para participação na pesquisa, na terceira etapa, quatro trabalhadores foram sorteados no grupo com maior e quatro no grupo com menor razão de consultas compartilhadas nas categorias profissionais identificadas.

$\mathrm{Na}$ quarta etapa, foi solicitado ao entrevistado do NASF que indicasse, para compor uma lista de sorteio, quatro profissionais, entre médicos e enfermeiros das equipes de saúde da família, que na opinião deles, colaborassem bastante ou colaborassem pouco com o seu trabalho.

Os dados da pesquisa foram obtidos através de entrevistas em profundidade ${ }^{19}$, com os profissionais selecionados. As entrevistas foram orientadas por um roteiro com questões relativas ao perfil profissional e sobre aspectos relacionados à visão do profissional sobre o trabalho compartilhado, ao processo de comunicação, às funções nucleares e periféricas de cada profissional e às 
condições, capacidades e conhecimentos utilizados para melhor interação profissional.

As entrevistas foram gravadas e posteriormente transcritas. Para a interpretação do material, utilizamos a análise de conteúdo, na vertente temática ${ }^{20,21}$. A partir de leituras repetidas e em profundidade do material empírico, foram identificadas as unidades de conteúdo. Essas unidades foram organizadas em temas afins levando-se em consideração os determinantes sistêmicos, organizacionais e interacionais da colaboração interprofissional ${ }^{22}$. Este agrupamento temático permitiu a identificação das categorias de análise. O software QSR nVivo 9 foi utilizado para auxílio na organização e tratamento dos dados qualitativos.

A pesquisa foi aprovada pelos comitês de ética em pesquisa da Secretaria Municipal de Saúde de São Paulo e da Faculdade de Saúde Pública da Universidade de São Paulo. Todos os participantes da pesquisa assinaram o termo de consentimento livre e esclarecido, de acordo com a Resolução 196/9623 do Conselho Nacional de Saúde. Para facilitar o acesso às fontes de pesquisa e preservar a identidade dos participantes, optou-se pelo uso das siglas (AS - Assistente Social, E - Enfermeiro, FA - Fisioterapeuta, FO - Fonoaudiólogo, M Médico), seguidas de um número, de acordo com a ordem de realização das entrevistas.

\section{Resultados}

Participaram do estudo sete apoiadores e oito profissionais pertencentes a equipes de referência, sendo dois assistentes sociais, quatro enfermeiros, três fisioterapeutas, dois fonoaudiólogos e quatro médicos. Desse total, 66,6\% eram do sexo feminino e apresentaram idade média de 34,3 anos. A maioria havia concluído sua graduação há mais de nove anos e 40\% deles possuíam curso de especialização em sua área de atuação profissional.

A análise do material permitiu o agrupamento das percepções em várias unidades de sentido e para efeito deste artigo, foram consideradas as categorias: interação profissional e metas de pro-

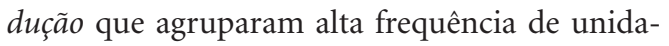
des de sentido, apresentando relevância para a temática desta pesquisa. Para ilustrar as categorias, serão apresentados alguns excertos das entrevistas.

\section{Interação profissional}

A categoria interação profissional reuniu as perspectivas dos entrevistados a respeito da cooperação e do apoio matricial na ESF, e as percepções relacionadas a como os profissionais constroem e traduzem as características da interação na produção do cuidado, incluindo os arranjos utilizados para organizar o trabalho compartilhado e criar condições para a colaboração na ESF. Entre as fontes de apoio à colaboração interprofissional destacaram-se: disposição dos profissionais, flexibilidade e abertura para colocar em ação interesses subjetivamente compartilhados e a postura de acolher as solicitações da equipe de referência. Tal postura favoreceria trocas entre os profissionais e a corresponsabilização dos casos.

Características profissionais apontadas como apenas assistir o trabalho do outro, não se envolvendo, e a dificuldade de compreensão do trabalho compartilhado parecem representar obstáculos ao apoio matricial. Os profissionais não identificaram essas características como falhas na colaboração, mas as indicaram como possíveis barreiras para a ação conjunta, no que se refere à interação profissional.

Ao ingressar na ESF, NASF utiliza da reunião da equipe de saúde da família para iniciar seu trabalho de apoio, chamando-a de reunião de matriciamento, quando ocorre a sua participação. Esta reunião se mostrou como um espaço importante para a realização do trabalho compartilhado, na medida em que são realizadas discussões de casos, planejamento e articulação de ações.

[...] o apoio matricial é feito junto com as equipes de saúde da família [...]. A equipe nuclear identifica a demanda [...], a gente discute pra propor a ação, que é, na verdade, o matriciamento. [...] ai a gente define se vai fazer abordagem grupal, se abordagem individual [...]. (AS2)

[...] fazemos reuniões de equipe, onde, a partir dali, pensamos estratégias de atendimento. Dali saem os casos, as discussões de caso, as propostas de projetos terapêuticos pra variadas famílias. (AS1)

A participação dos profissionais do NASF na reunião apresentou variedade de composição: (1) participação de toda a equipe NASF, (2) participação na forma de "miniequipes" temáticas e (3) interação por meio de profissionais de referência. As justificativas para a adoção dessas diferentes formas apontaram para visões distintas, desde percepções voltadas para melhor aproveitamento dos momentos de discussão até aspectos relacionados à organização da agenda. Percebe-se, assim, esforços para ampliar o nível de interação 
e reduzir a fragmentação do cuidado por categoria profissional.

Foram encontradas diferentes percepções sobre a reunião de matriciamento. Parte dos entrevistados entendeu que as reuniões possibilitavam um espaço de aprendizado, troca de saberes, aprimoramento da prática, trazendo benefícios para a sua atuação profissional. Relataram que as trocas vivenciadas traziam resultados positivos para o usuário e o serviço, e consideraram as reuniões entre os profissionais de ESF e NASF como um recurso para o planejamento das ações.

[...] discutir o caso e solucionar ou traçar uma estratégia pra fazer o atendimento. [...] identificar quem é o profissional que pode tá trabalhando em cima desse caso e até pra fazer como se fosse uma educação com a equipe. [...] ele pode tá pegando essa experiência pra poder orientar a família na área dele. Então esse é o apoio matricial, essa reunião que a gente faz de discussão de caso, uma troca de experiência. (AS2)

Outras percepções identificaram a reunião de matriciamento como um recurso que não atendia às necessidades do paciente. Para alguns profissionais, a reunião seria perda de tempo, pois o encaminhamento ao especialista ao invés da discussão do caso com a equipe de apoio traria um benefício mais efetivo à necessidade do paciente.

Eu ocupo o tempo com matriciamento que, às vezes, eu poderia tá fazendo outras coisas. E eu preciso da consulta, eu não preciso de outra coisa. (M3)

Esse aspecto emergiu como um forte indicativo das dificuldades encontradas pelos profissionais quando se buscava um olhar mais ampliado para a abordagem dos casos. Para alguns profissionais, a discussão de caso era melhor utilizada como um recurso para encaminhamentos, no sentido de responder de forma rápida às demandas que chegam à equipe de saúde da família.

Quanto à visão sobre as ações de apoio, para alguns entrevistados, elas seriam uma resposta às necessidades da ESF para assistir usuários cujo grau de complexidade exigiria cuidados multiprofissionais.

[...] eu acho que precisava de uma equipe de NASF pra cada UBS. [...] Tenho uma demanda muito grande [...], muita coisa fica aliviada quando eu passo pra equipe do NASF. Não que eles possam absorver tudo. Eles também têm carência. Mas eles aliviam meu serviço e muito [...]. (M4)

Lógico que quando a gente tem um acúmulo de problemas, de comorbidades e aí o paciente já é muito mais resistente [...]. Posso fazer uma compartilhada, posso fazer um grupo [...] Então a gente sabe o momento que você, até onde você conse- gue ir sozinho [...] mas tem uma hora ou outra que precisa realmente, precisa de uma avaliação mais técnica mesmo. (E1)

É um paciente que precisa de múltiplos tratamentos que o NASF pode oferecer. (M4)

Como a complexidade dos casos exige um olhar mais abrangente, o trabalho compartilhado é um recurso que amplia a atuação profissional para outras áreas de conhecimento. A adoção do apoio matricial, para alguns, parece alterar os processos e configurações habituais de trabalho na ESF, como observado na narrativa de AS1, quando descreve as mudanças na atuação profissional no NASF. Na narrativa de FA1, o profissional relata uma ampliação das atribuições profissionais, que passa a priorizar as ações de apoio matricial e não apenas ações específicas.

[...] a gente não estava preparado. [...] A gente estava acostumado, vindo da faculdade, acostumado com a retórica, com um modus operandi. Aí eu chego lá e é tudo diferente. Eu vejo as pessoas ali e eu não posso sair catando elas e tá atendendo porque eu não sou plantão social, eu tenho que atender as equipes e referenciar as equipes. E aí sim, atender as pessoas baseado no que elas propõem. (AS1)

[...] porque como é um núcleo de apoio [...] é matriciar, independente de sua categoria, com toda aquela vivência que você teve. [...] numa reunião de matriciamento [...], eles me trouxeram um caso e na discussão [...] entrou num consenso, devido à vivência de cada um, que é necessário uma consulta com o psicólogo. Então eu, enquanto representante NASF, vou tentar direcionar quais as ações e atribuições que a minha equipe vai ter. Eu tenho que ter isso muito bem entendido, pra conseguir direcionar junto com a equipe da estratégia de saúde da família, o que vai ser melhor. (FA1)

Além do entendimento do apoio como um alívio para as demandas da ESF, por outro lado, alguns profissionais identificaram com o apoio um aumento de trabalho, pois o acompanhamento dos casos seria realizado pela própria ESF. Isso acaba por interferir nas estratégias de colaboração.

Então, o enfermeiro faz uma consulta compartilhada com médico psiquiatra [...] o médico psiquiatra vai dar aquele monte de orientação [...]. Quem vai fazer esse acompanhamento, fazer essa conversa depois de novo é o enfermeiro [...]. Tem demanda, agora não tem quem atenda. (E3)

Eu trago pro NASF, o NASF quer em vez de marcar consulta, me ajudar. Só que eu já tenho uma demanda grande, eu não preciso de alguém que me diga o que fazer, que isso me atrapalha muito. Que dai eu vou ter que reagendar esse paciente em curto prazo e eu não tenho nem vaga. (M3) 
Pela demanda do lugar. Parece assim que eles são engolidos mesmo. Eles até podem entrar com a proposta, sabendo o que é atenção primária, mas chega o médico e a enfermeira com aquela agenda enorme de hipertenso, diabético [...]. Então, acaba não conseguindo realizar o que eles também realmente gostariam. [...] Eles estão muito ocupados com a questão do atendimento [...] fazendo trabatho de outros setores. (FA2)

Ao ingressar na atenção primária, a equipe NASF passa a apoiar as ações da ESF, atuando de forma conjunta. Para tanto, os profissionais relatam certa dificuldade em desempenhar os papéis profissionais no serviço, em virtude da grande demanda de trabalho. Isso acaba interferindo nas solicitações de apoio pela ESF e também no que esperam enquanto apoio. Para alguns profissionais, a insuficiente rede de serviços impõe importantes limitações ao trabalho do NASF e também às ações compartilhadas.

A gente vem com a proposta feita, das nossas diretrizes, do que a gente sabe o que é atenção primária, do que a gente espera que seja atenção primária e a gente cai numa demanda já existente. Então, por mais que eu queira fazer ações de promoção, de prevenção, eu não consigo porque a Estratégia está cuidando de uma população totalmente adoecida e sem rede. (FA2)

[...] eu acho que não deveria ter NASF. Eu acho que deveria ter ambulatório de especialidades direto. [...] Eu sei que pode soar negativo isso, mas é a minha realidade. Às vezes me atrapalha mais do que me ajuda. (M3)

Para alguns profissionais, haveria uma inadequação da proposta ao se compartilhar o caso com o especialista e a responsabilidade permanecer centrada na ESF, o que pode ser observado na narrativa de M3, quando relata que a estrutura do apoio matricial não permite a transferência de responsabilidades.

[...] eu aprendi que tem casos que eu levo pro NASF, tem casos que eu não levo, mesmo que eu tenha o profissional do NASF. Eu encaminho pra fisioterapia no ambulatório fora, eu encaminho pro ginecologista de um ambulatório fora. Não trago pro NASF. Porque daí mais me atrapalha do que me ajuda. E não é culpa, às vezes, do NASF. É a estrutura dele que faz isso atrapalhar a gente. (M3)

Fator importante destacado nas narrativas é relativo à insuficiência da rede e sua precária estruturação. Devido às situações de maior complexidade e às dificuldades de articulação do trabalho da ESF com os demais serviços da rede de saúde e de outros setores da sociedade, o trabalho essencial do NASF pode se alterar, assumindo re- levância o apoio aos casos que seriam compartilhados com estes setores.

A demanda de trabalho da ESF e a rede de apoio insuficiente parecem representar importantes barreiras para o trabalho compartilhado. A fim de superá-las, alguns arranjos específicos são colocados em prática para estabelecer a colaboração no cotidiano de trabalho. A percepção dos entrevistados sobre a utilização desses arranjos mostra que o trabalho permanece ainda pouco integrado e os espaços para efetivar a colaboração, limitados.

\section{Metas de produção}

O material das entrevistas denota que o planejamento e agendamento das ações junto à ESF foram, em grande parte, determinados por metas de produção.

Alguns achados relacionavam a dificuldade em adequar agendas ESF e NASF, visando o alcance das metas de produção da ESF (número alto de consultas específicas e agendas pouco flexíveis). Neste caso, as metas de produção estabelecidas entre a organização social e a secretaria municipal de saúde, representariam uma barreira para o desenvolvimento das atividades compartilhadas com o NASF.

Eu acho que este trabalho ainda não ocorre como poderia ocorrer, muito da justificativa vem das metas e é sempre esta a justificativa assim. Meta, meta, meta, porque a consulta é de 15 minutos, do médico. (AS1)

[...] às vezes, a gente planeja algumas ações que seriam necessárias [...] a participação da estratégia, dos profissionais da estratégia de saúde. [...] 'Oh! Eu não posso, porque eu tenho que terminar as minhas VD. Eu não posso porque eu tô em consulta [...] tenho que atingir a minha meta?. Então, isso dificulta. [...] A organização dele fica tudo em torno da meta, do ' $X$ ' de grupos, do ' $X$ ' de VD, de consulta. (FA1)

Os profissionais discutem a cobrança das metas, questionam o seu cumprimento e a operacionalização do apoio. Frente às narrativas, depreende-se que as metas estão descoladas e não se ajustam à realidade de um trabalho compartilhado entre NASF e ESF, a partir das demandas sociais presentes no território.

[...] eles querem que a gente faça. Eles cobram as consultas compartilhadas, mas a gente fala: 'Vocês podem cobrar. Mas enquanto a gente não sentar pra rediscutir a agenda e a produção, a forma de trabalho, o processo de trabalho das equipes de saúde da família, não tem como eu bater meta?. (FO2) 
E é frustrante, porque eu não vou deixar de atender aquela pessoa, fazer uma visita, por conta de uma meta. E na verdade, depois, a sensação de discutir essas metas é que a gente não tá fazendo o trabalho direito. (FA2)

Este tipo de perspectiva parece refletir um anseio dos profissionais em participar da construção de mecanismos de avaliação do trabalho, não apenas com o uso de instrumentos de aferição de processo, mas principalmente com a adoção de parâmetros relacionados aos resultados do trabalho.

Mas e a qualidade do trabalho e aquela retórica toda de clínica ampliada, de atendimento humanizado? Entendeu? Então, falar de atendimento humanizado e de metas são coisas que, prá mim, não batem. Quando tiver um, não vai ter o outro. Simples. [...] mesmo que as pessoas sejam capacitadas, [...] quando ele pegar aquele papel com 20 consultas e vai atender vinte consultas, independente de tudo que ele tenha feito. (AS1)

\section{Discussão}

A colaboração interprofissional tem sido identificada como uma estratégia para um cuidado de saúde mais qualificado, ampliado, efetivo. O interesse nessa temática tem crescido nas últimas décadas, em parte pelo aumento da complexidade do cuidado e pela melhor compreensão dos determinantes do processo saúde-doença. Também, o aumento dos custos com o cuidado, advindos da especialização médica e do avanço tecnológico, que reforçam a necessidade de redesenhar as práticas em saúde ${ }^{24}$. A colaboração interprofissional também tem sido pauta nas discussões das políticas de saúde, a fim de melhorar a qualidade e o acesso aos serviços, na perspectiva de uma atenção à saúde mais contínua e abrangente. Esta tendência em adotar novas formas de organização dos serviços requer, não apenas, a implementação de novas áreas e funções nas estruturas organizacionais existentes, mas também o desenvolvimento de práticas de cuidado compartilhado ${ }^{25}$.

A agregação de outras categorias profissionais por meio do NASF, tem proporcionado a implementação de diferentes formas de atuação, ampliando as possibilidades de cuidado oferecido na ESF. Porém, os resultados observados mostram que ainda persistem visões de trabalho individualizado e pouco integrado.

Diante de determinados casos, a primeira atitude seria recorrer ao encaminhamento para um serviço externo ao invés de buscar, com a equipe de apoio, a cogestão de projetos terapêuticos centrados no paciente. Essas diferentes visões parecem marcadas por diferentes lógicas de produção do cuidado. Aparentemente, alguns profissionais parecem operar na lógica do encaminhamento e esperam ações da equipe e respostas da organização a ela coerentes, o que implicaria na expansão dos serviços especializados. Outros profissionais parecem apostar mais no trabalho compartilhado propiciado pelo apoio matricial.

A finalidade do apoio especializado matricial é contribuir para a qualificação da produção do cuidado em saúde. O vínculo e a comunicação entre os integrantes das equipes (referência e apoio) poderiam facilitar a interação e melhorar o grau de colaboração entre os profissionais ampliando as possibilidades da atenção ${ }^{13,14}$. No lugar da transferência de responsabilidades de uma equipe para a outra, busca-se a corresponsabilidade entre as equipes de referência e de apoio. Com isso, os encaminhamentos deixariam de ser automáticos e passariam a ser discutidos em equipe $^{26}$.

Os resultados mostraram que agrupar profissionais em equipes não necessariamente se traduz em uma prática colaborativa. A alteração da lógica dos encaminhamentos para especialistas e o compartilhamento de responsabilidades, decisões, visões e práticas ${ }^{5}$ na produção do cuidado longitudinal de usuários e famílias permanece, segundo os resultados, como um importante desafio ${ }^{11}$.

Essas distintas percepções podem indicar que as predisposições subjetivas não são as mesmas entre as diferentes categorias, nem entre profissionais de uma mesma categoria ${ }^{14,27}$.

Além disso, a proposta de apoio matricial especializado produz tensões na lógica da estrutura organizacional dos serviços de saúde. Essa lógica reforça o isolamento profissional e reproduz a fragmentação dos processos de trabalho, dificultando a colaboração interprofissional ${ }^{13}$.

Portanto, duas questões complexas emergiram das entrevistas: a tensão entre a lógica profissional tradicional e a lógica da colaboração ${ }^{27}$ e a tensão entre um modelo centrado em procedimentos especializados e outro cujo centro deveria ser as necessidades de saúde, tanto em sua dimensão individual quanto coletiva. A primeira questão diz respeito à oposição entre padrões distintos de desenvolvimento e reconhecimento profissional: de um lado, uma perspectiva de diferenciação, e de outro, uma perspectiva de integração na qual valores de preservação da independência profissional, de concentração de poder e ascendência sobre outras categorias são 
colocados em cheque para dar lugar a decisões compartilhadas com outros profissionais e arranjos centrados no usuário. Em relação à segunda tensão, os procedimentos especializados funcionariam como serviços de apoio, sem ocupar o centro da produção do cuidado, e está associada à implementação do apoio especializado matricial nas unidades de atenção primária que problematiza o caráter uniprofissional que tradicionalmente rege os critérios de tomada de decisão clínica. Conforme Mendes ${ }^{28}$, uma das dimensões requeridas para as mudanças no modelo de atenção à saúde é a transição de uma atenção prescritiva e centrada na doença para uma atenção colaborativa e centrada na pessoa e na família.

No município em questão, os profissionais da ESF/NASF orientam seu trabalho, pautados em grande medida, por metas de produção de consultas estabelecidas por meio de contratos de gestão local do SUS. O NASF por ter como objetivo, o apoio à ESF, organizaria seu trabalho a partir das demandas das equipes de saúde da família. Como a ESF organiza seu trabalho a partir dessas metas, o NASF, em consequência, também compõe seu trabalho condicionado pelas metas de produção da ESF.

Em São Paulo, metas de produção foram implantadas como um dos principais indicadores de monitoramento e avaliação dos contratos de gestão ${ }^{29}$. A despeito de ter sido constatada uma orientação para o plano de trabalho não ficar voltado apenas para o cumprimento dessas metas ${ }^{29}$, o que foi observado com base nas entrevistas é que, independente da realidade de cada contexto em que o profissional está inserido, há indicadores de produção para cada categoria inserida na ESF. As metas referem-se apenas ao número de procedimentos realizados pelos profissionais da ESF. São utilizadas como instrumento de avaliação do trabalho. Porém esta avaliação permanece quantitativa, baseada em procedimentos e limitada ao processo de trabalho nas equipes.

A prática de prestação de contas e a responsabilidade de cada profissional perante usuários/ pacientes estão relacionadas com a possibilidade de controle do processo de trabalho ${ }^{30}$. Para tanto, quando se pensa em mudança dos processos de trabalho, enfatizando relações mais horizontais entre os profissionais das equipes, estes mecanismos também precisam ser redefinidos de forma compartilhada e comunicativa. As metas relacionadas apenas ao processo de trabalho provocam uma alteração no modo de se realizar o apoio matricial especializado. $\mathrm{O}$ trabalho que deveria ser realizado a partir das dificuldades da equipe de referência e orientado por parâmetros clínicos, epidemiológicos e sanitários encontrados no território ${ }^{31}$, passa a ser planejado em torno do cumprimento de metas de produção de consulta, sem levar em consideração os resultados finais a serem alcançados.

As dificuldades de operacionalização do trabalho da ESF e do NASF podem ser consideradas expressões dessa política de gestão centrada em metas de produção, que tem implicações para as relações de interação e, consequentemente, para o desenvolvimento de um trabalho colaborativo.

Uma gestão com base em resultados relativos ao controle das doenças e agravos da população, e não apenas centrada em metas de produção, teria que estar apoiada ao menos em indicadores epidemiológicos e sanitários relativos ao território. Com isso, verifica-se a necessidade de repensar a gestão de forma que o processo de trabalho seja analisado sob o ponto de vista do seu impacto coletivo, e não na singularidade da produção individual de cada profissional. Metas preestabelecidas pactuadas em regime de corresponsabilidade e compromisso mútuo entre trabalhadores e nível diretivo, avaliadas periodicamente, poderiam possibilitar uma maior responsabilização sobre os resultados desejados ${ }^{32}$.

Além disso, a baixa articulação da rede assistencial se configura como um entrave estrutural para efetivação do modelo de apoio, bem como para a construção da integralidade. A dificuldade de compartilhar os casos entre os serviços (coordenação da atenção) e manter a longitudinalidade do cuidado na ESF seriam alguns dos efeitos mais visíveis dessa limitação imposta pelo baixo grau de articulação e de compromissos pactuados entre os serviços ${ }^{33}$.

A utilização do apoio matricial especializado como instrumento cotidiano de trabalho pressupõe certo grau de transformação na organização e funcionamento dos serviços e sistemas de saúde. Para que o modelo de apoio seja efetivo, é necessária a implementação de instrumentos e dispositivos organizacionais que favoreçam o compartilhamento de responsabilidades entre as equipes. Os profissionais são importantes para a consolidação dessa estratégia de atenção, determinando, de acordo com sua visão, disposições favoráveis ou não para a colaboração. As ações compartilhadas permanecem como um desafio, na questão organizacional da articulação e do agendamento entre as equipes e profissionais ${ }^{14}$.

Com o apoio matricial, há uma tentativa na ESF de se estabelecer gradualmente a lógica da colaboração interprofissional. A implantação do 
NASF requer movimentos de mudança organizacional e institucional nos serviços de saúde a fim de se estabelecer como apoio à inserção da ESF na rede de serviços do SUS.

$\mathrm{Na}$ presença ou não de entraves estruturais, os profissionais das equipes, não perdem sua condição de protagonistas das práticas de saú$\mathrm{de}^{31}$. Admitir tal premissa implica considerar que a obstrução ou efetivação das propostas de colaboração interprofissional, no âmbito do NASF e da ESF, é relacionada, em uma parte importante, aos sentidos e significados que os profissionais dão à sua atuação, ao papel da ESF e às diretrizes de trabalho. Conforme Merhy ${ }^{31}$, as ações dos profissionais de saúde sempre têm uma direcionalidade, explícita ou implícita, quanto ao tipo de projeto ou aposta na qual o sujeito do trabalho se insere, refletindo as tensões entre o cuidado centrado nos procedimentos ou nos usuários; entre um agir privado ou público; e entre as distintas intenções em torno do que são o objeto e o sentido das ações de saúde.

Diante do exposto, é nítida a necessidade de aperfeiçoar a gestão do trabalho dotando os serviços de mais recursos de apoio à colaboração interprofissional, que precisa ser entendida não apenas como um esforço individual e pessoal do trabalhador em saúde, mas também como um esforço coletivo e ampliado de diversos agentes (profissionais, gestores e usuários) e componentes do sistema (gestão do trabalho, sistema de informação, entre outros). A implementação de um processo de construção dialogada e compartilhada de objetivos comuns entre apoio e referência exige uma gerência comprometida com a superação de suas barreiras estruturais.

Para tanto, é preciso ampliar o conhecimento e entendimento sobre os processos colaborativos na APS, reconhecendo o seu potencial de contribuição no campo da gestão do trabalho e da reforma dos modelos de atenção ${ }^{13,27}$.
Apontam-se, como limitação do estudo, dificuldades inerentes às pesquisas qualitativas baseadas principalmente em entrevistas. É reconhecido que elas não oferecem dados sobre o que os sujeitos fazem, mas sim sobre o que eles relatam sobre uma determinada questão, e principalmente, de que modo relatam, o que pode ser muito importante para a compreensão do significado que certa questão assume para determinado entrevistado. Outros estudos e abordagens são necessárias, voltados à compreensão das tensões que emergem quando novos arranjos são colocados em prática no processo de produção do cuidado.

\section{Conclusões}

A Saúde da Família representa uma estratégia para tornar a atenção primária um componente estruturante da transformação do modelo de atenção em saúde no Brasil. Com a implantação do Núcleo de Apoio à Saúde da Família (NASF) são incorporados outros profissionais a fim de reforçar e ampliar as ações de APS no contexto brasileiro. No modelo de apoio matricial adotado com o NASF, há uma tentativa na ESF de se estabelecer gradualmente a lógica da colaboração interprofissional no cotidiano do trabalho. Entretanto, observa-se insuficiência de dispositivos organizacionais para apoiar o trabalho compartilhado na ESF.

Os resultados apresentados podem contribuir para a inserção da colaboração interprofissional na agenda estratégica para a reforma do sistema de saúde brasileiro e, mais especificamente, para a atenção primária à saúde, não apenas com a implantação de novos dispositivos como o apoio matricial, por meio do NASF, mas também, no desenvolvimento de novas práticas de atenção à saúde que coloquem as necessidades das pessoas e das famílias no centro da produção do cuidado. 


\section{Colaboradores}

CG Matuda contribuiu na concepção do estudo, coleta de dados, transcrição e análise das entrevistas, interpretação dos dados e redação do manuscrito. NRS Pinto e CL Martins colaboraram na concepção do estudo e revisão crítica do conteúdo intelectual do artigo e aprovação da versão final do manuscrito. P Frazão colaborou na concepção do estudo, interpretação dos dados, redação, revisão crítica do conteúdo intelectual do artigo, aprovação da versão final do manuscrito.

\section{Agradecimentos}

Os autores agradecem o apoio da Coordenação da Atenção Básica - Secretaria Municipal da Saúde da Prefeitura Municipal de São Paulo - no acesso aos relatórios de procedimentos realizados pelos profissionais NASF/SIGMA. À Associação Congregação de Santa Catarina, ao Instituto Israelita de Responsabilidade Social, ao Centro Universitário Adventista de São Paulo - Administração PSF UNASP e à Associação Saúde da Família pelo acesso ao campo da pesquisa e aos profissionais que participaram das entrevistas.

\section{Referências}

1. Organización Mundial de la Salud (OMS). La Atención Primária de Salud: más necesaria que nunca. Informe sobre la salud en el mundo. Genebra: OMS; 2008.

2. Dussault G. The health professions and the performance of future health systems in low-income countries: Support or obstacle? Soc Sci Med 2008; 66(10):20882095.

3. World Health Organization (WHO). Framework for Action on Interprofessional Education and Collaborative Practice. Genebra: WHO/HRH/HPN/10.3; 2010 [acesso 2011 fev 12]. Disponível em: http://www.who.int/ hrh/nursing_midwifery/en/

4. Feeley N, Gottlieb LN, Dalton C. The collaborative partnership approach to care: a delicate balance. Toronto: Elsevier Mosby; 2005.

5. D'Amour D, Ferrara-Videla M, Rodriguez LSM, Beaulieu MD. The conceptual basis for interprofessional collaboration: Core concepts and theorical frameworks. J Interprof Care 2005; (Supl. 1):116-131.

6. Oandasan I (University of Toronto, Toronto Western Hospital, Toronto, CA). Interdisciplinary education for collaborative, patient-centred practice. Research and Findings Report. Ottawa: Health Canada; 2004.

7. Way D, Jones L, Baskerville B, Busing N. Primary health care provided by nurse practitioners and family pshysicians in shared practice. JAMC 2001; 165(9):12101214.

8. Shaw A, Lusignan S, Rowlands G. Do primary care professionals work as a team: a qualitative study. J Interprof Care 2005; 19(4):396-405.

9. Giovanella L, Mendonça MHM. Atenção Primária à Saúde. In: Giovanella L, Escorel S, Lobato LVC, Noronha JC, Carvalho AI, organizadores. Políticas e Sistema de Saúde no Brasil. Rio de Janeiro: Editora Fiocruz; 2008. p. 575-625.

10. Matuda CG, Aguiar DML, Frazão P. Cooperação interprofissional e a Reforma Sanitária no Brasil: implicações para o modelo de atenção à saúde. Saude Soc. 2013; 22(1):173-186.

11. Brasil. Ministério da Saúde (MS). Diretrizes do NASF Núcleo de Apoio à Saúde da Família. Brasília: MS; 2009. (Cadernos de Atenção Básica, n. 27, versão preliminar).

12. Brasil. Portaria MS/GM 2488, de 21 de outubro de 2011. Aprova a Política Nacional de Atenção Básica, estabelecendo a revisão de diretrizes e normas para a organização da Atenção Básica, para a Estratégia Saúde da Família (ESF) e o Programa de Agentes Comunitários de Saúde (PACS). Diário Oficial da União 2011; 21 out.

13. Campos GWS. Equipes de referência e Apoio Especializado Matricial: um ensaio sobre a reorganização do trabalho em saúde. Cienc Saude Colet 1999; 4(2):393403. 
14. Campos GWS, Domitti AC. Apoio matricial e equipe de referência: uma metodologia para a gestão do trabalho interdisciplinar em saúde. Cad Saude Publica 2007; 23(2):399-407.

15. Franco TB, Merhy EE. Programa Saúde da Família (PSF): contradições de um programa destinado à mudança do modelo tecnoassistencial. In: Mehry EE, Magalhaes Jr HMM, Rimoli J, Franco TB, Bueno WS. O trabalho em saúde: olhando e experenciando o SUS no cotidiano. $4^{\text {a }}$ ed. São Paulo: Hucitec; 2007.

16. São Paulo. Lei no 14.132, de 24 de janeiro de 2006. Dispõe sobre a qualificação de entidades sem fins lucrativos como organizações sociais. Diário Oficial da Cidade de São Paulo 2006; 25 jan.

17. Bousquat A, Cohn A, Elias PE. Implantação do Programa Saúde da Família e exclusão sócioespacial no Município de São Paulo, Brasil. Cad Saude Publica 2006; 22(9):1935-1943.

18. Patton MQ. Qualitative research \& evaluation methods. Thousand Oaks: Sage; 2002.

19. Taylor SJ, Bogdan R. Introduction to qualitative research methods: the search for meanings. New York: John Wiley; 1984.

20. Minayo MCS. O desafio do conhecimento: pesquisa qualitativa em saúde. $8^{\mathrm{a}}$ ed. São Paulo: Hucitec; 2004.

21. Bardin L. Análise de conteúdo. São Paulo: Editora 70; 2008.

22. San Martin-Rodriguez L, Beaulieu MD, D’Amour D, Ferrara-Videla M. The determinants of sucessfull collaboration: A review of theorical and empirical studies. $J$ Interprof Care 2005; (Supl. 1):132-147.

23. Brasil. Ministério da Saúde (MS). Conselho Nacional de Saúde. Resolução no 196 de 10 de outubro de 1996. Diretrizes e Normas Regulamentadoras de Pesquisas Envolvendo Seres Humanos. Diário Oficial da União 1996; 16 out.

24. Gaboury I, Bujold M, Boon H, Moher D. Interprofessional collaboration within Canadian integrative healthcare clinics: key components. Soc Sci Med 2009; 69(5):707-715.

25. D'Amour D, Goulet L, Labadie JF, San Martín-Rodriguez, Pineault R. A model and tipology of collaboration between professionals in healthcare organizations. BMC Health Services Research. 2008; 8:188 [cited 2010 Jun 15]. Available from: http://www.biomedcentral. com/1472-6963/8/188

26. Figueiredo MD, Campos RO. Saúde Mental na atenção básica à saúde de Campinas, SP: uma rede ou um emaranhado? Cienc Saude Colet 2009; 14(1):129-138.

27. Furtado JP. Equipes de referência: arranjo institucional para potencializar a colaboração entre disciplinas e profissões. Interface (Botucau) 2007; 11(22):239-255.
28. Mendes EV. As redes de atenção à saúde. Brasília: Organização Pan-Americana da Saúde; 2011.

29. São Paulo. Secretaria Municipal de Saúde. Instrumento normativo para monitoramento técnico, administrativo e financeiro dos convênios da Estratégia Saúde da Família no âmbito do município de São Paulo. São Paulo: Coordenação de Atenção Básica; 2009.

30. Peduzzi M, Carvalho BG, Mandú ENT, Souza GC, Silva JAM. Trabalho em equipe na perspectiva da gerência de serviços de saúde: instrumentos para a construção da prática interprofissional. Physis 2011; 21(2):629-646.

31. Merhy EE. Todos os atores em situação, na saúde, disputam a gestão e a produção do cuidado. In: Merhy EE. Saúde: a cartografia do trabalho vivo. São Paulo: Hucitec; 2007. p. 149-178.

32. Ditterich RG, Moysés ST, Moysés SJ. O uso de contratos de gestão e incentivos profissionais no setor público de saúde. Cad Saude Publica 2012; 28(4):615-627.

33. Cunha GT, Campos GWS. Apoio Matricial e Atenção Primária em Saúde. Saude Soc. 2011; 20(4):961-970.

Artigo apresentado em 19/03/2014

Aprovado em 19/11/2014

Versão final apresentada em 21/11/2014 